\title{
The analysis of vaginal hysterectomy results depending on the uterine size
}

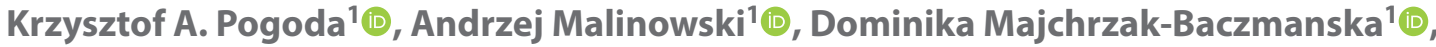 \\ Agnieszka Wosiak² \\ ${ }^{1}$ Clinic of Surgical, Endoscopic and Oncological Gynecology, Institute of Polish Mother's Health Center Lodz, Poland \\ ${ }^{2}$ Institute of Information Technology, Lodz University of Technology, Poland
}

\begin{abstract}
Objectives: Vaginal hysterectomy is one of the oldest but still rarely used minimally invasive techniques. Although new surgical methods making use of robots in laparoscopy have been introduced recently, when compared with vaginal hysterectomy, these approaches do not offer significant benefits for the patients and the doctors operating on them.

The purpose of this study was a thorough analysis of vaginal removal of non-prolapsed uterus with benign pathology.

Material and methods: The analysis included data of 1148 women who underwent vaginal hysterectomy in the Clinic of Surgical, Endoscopic and Oncological Gynecology between 2002 and 2014. A group of patients operated on were assessed, and data from the surgeries were obtained paying attention to such aspects as the operating time, the evaluation of morphotic blood elements, the type of perioperative complications, and the length of postoperative hospital stay. Additionally, all vaginal hysterectomies were divided into groups and analyzed taking into consideration uterus weight.

Results: Vaginal hysterectomy was performed even in cases of earlier abdominal surgeries. The mean operating time was and $69.51 \pm 28.32$ minutes. The patients left hospital after 2.93 days on average. The mean uterus weight was $179.69 \pm 113.54 \mathrm{~g}$.

What is important, the enlarged uterus was not a significant obstacle during the surgery. In case of heavy uteri of more than $580 \mathrm{~g}$, when the fundus of the uterus reached above the navel, the attention was drawn to the need for careful preparatory procedures, which reduced the number of perioperative complications and thus had a significant influence on the length of the operation $(p=0.0170)$.

Conclusions: Vaginal hysterectomy is an operating technique which is relatively easy to perform and safe for the patients because it involves a slight decrease of morphotic blood elements and a small number of mid-and postoperative complications. Vaginal hysterectomy is not a contraindication in case of large uteri, even those of more than $1000 \mathrm{~g}$; however, in such cases, a longer operating time and an increased number of perioperative complications must be taken into consideration. Key words: vaginal hysterectomy; large uterus; reducing uterine size; minimally invasive technique
\end{abstract}

Ginekologia Polska 2021; 92, 5: 339-343

\section{INTRODUCTION}

Hysterectomy is still one of the most frequently performed gynecologic-obstetrical operations. There is abdominal hysterectomy $(\mathrm{AH})$, vaginal hysterectomy $(\mathrm{VH})$ and laparoscopic hysterectomy (LH). There are also techniques that combine laparoscopic and vaginal hysterectomy (LAVH) and surgeries which make the use of robots.

As the statistical evidence worldwide and nationwide shows, despite the benefits of vaginal removal of uterus, abdominal hysterectomy has been the most frequent type of operation for the last couple of decades. This stems from the fact that a large group of gynecologists prefer traditional methods, which are often the only ones in which they gained experience in the course of their work. Abdominal hysterectomy relates to a longer hospital stay and a longer recovery time, greater pain and a higher risk of infection. On the other hand, minimally invasive techniques $(\mathrm{VH}, \mathrm{LH})$ are associated with a shorter hospital stay and a shorter recovery time [1]. A majority of elderly surgeons are not able, or perhaps willing, to change their operating habits, which often results in a lack of development and training of their younger colleagues in these minimally invasive techniques [2].

Nowadays, the crucial criteria on which the choice of the operating method is based should include the advantages

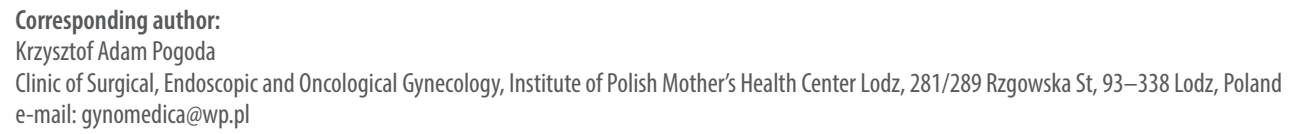


and disadvantages of particular operating techniques, the patient's well-being after the operation, the time of the return to regular life activity, the level of satisfaction with the performed operation and the experience and skills of the operating doctor [3].

While a variety of random or patient-dependent factors affect the choice of the operating method, the size of the uterus assessed clinically during the bimanual exam and ultrasonography is one of the main decisive factors when choosing which approach to take. In patients whose uterus does not exceed the size of that at the $12^{\text {th }}$ week of pregnan$c y$, or the uterine volume is not bigger than $250-300 \mathrm{~cm}^{3}$, vaginal hysterectomy seems to be the best solution [4]. In case of a bigger uterine size and volume, total laparoscopic hysterectomy (TLH) or a technique combining vaginal and laparoscopic hysterectomy (LAVH) are better options. Only if a laparoscopic technique was difficult or risky, should abdominal hysterectomy be considered.

Undoubtedly, with a growing experience in vaginal removal of the uterus, the size of uterus bigger than that 12 weeks pregnant and the volume exceeding $300 \mathrm{~cm}^{3}$ cease to be a contraindication for vaginal hysterectomy.

In case of significant uterine hypertrophy, it is necessary to use one or more techniques for reducing the size of uterus: hemisection, trachelectomy, wedging, coring, and myomectomy [5].

The most frequently used method is hemisection, which consists in cutting cervix and the body of the uterus in saggital plane. This technique facilitates access to the inside of the uterine body and allows for gradual enucleation of uterine myoma located in the closest proximity to the incision. The size as well as the location of myomas have an influence on how difficult the removal of uterus is. Using the vaginal method, it is easiest to enucleate myomas located on the posterior wall of the uterus. Myomas located on the anterior wall or near the uterine fundus are more difficult to enucleate. Intraligamentous myomas are a contraindication for transvaginal operation [3].

In a situation, when the uterus is enlarged due to adenomyosis, trachelectomy seems to be a better technique to reduce its size. This method involves separating cervix from the body of the uterus, which changes the shape of uterus from pear-shaped to apple-shaped allowing for its greater mobility. It makes it possible to turn the uterus around its own axis and as a result gain easier access to its anterior and posterior wall. This technique should be used not only in case of uterine hypertrophy but also decreased uterine mobility [5]. Another technique of uterus morcellation, also frequently used during vaginal operations, is the so-called coring which consists in circumferential intramuscular excising of the central core of tissue around the uterine cavity (preferably just under the level of the uterine isthmus) with the simultaneous pulling of the cervix. It causes progressive lengthening of the uterine body in longitudinal axis and delivering the uterus into vagina [3]. When other techniques fail, it might prove helpful to use wedge morcellation i.e., excising the uterus in pieces.

The purpose of this study was the analysis of the results of vaginal removal of non-prolapsed uterus with benign pathology, depending on the size of the uterus.

\section{MATERIAL AND METHODS}

In the time period between October 2002 and June 2014, 1148 vaginal removals of non-prolapsed uteri with benign pathologies were performed in the Clinic of Surgical, Endoscopic and Oncological Gynecology of the Polish Mother's Memorial Hospital Research Institute (ICZMP) in Lodz. This paper is a thorough retrospective medical record review.

The criteria qualifying for the operation were benign pathologies of the uterus requiring surgical intervention. Patients with genital static disorders as well as those suspected of neoplastic lesions in the area of pelvis minor were excluded from the study.

Basic demographic data such as age, body mass index (BMI) and past obstetric and surgical history were collected. Additionally, the operating time, the length of postoperative hospital stay, selected parameters such as the drop of hemoglobin and hematocrit as well as the type and number of complications were analysed.

All patients were divided into three groups depending on the weight of the removed uterus in order to evaluate surgical results: Group I uterus weight below $280 \mathrm{~g}$, Group II uterus weight between $280 \mathrm{~g}$ and $579 \mathrm{~g}$, and Group III uteri heavier than $580 \mathrm{~g}$.

As part of the statistical analysis basic measurements of structure description were assessed: arithmetic mean and standard deviation. Statistical significance of the differences in values obtained in the three groups was checked. The statistical significance level was set at $p \leq 0.05$. To determine differences in continuous data between the three groups regarding the weight of the removed uterus a single factor one-way analysis of variance (ANOVA) was used (for the variables having normal distribution) as well as the Kruskal-Wallis test (for non-parametric variables). Verification of the normality of distribution was conducted using The Saphiro-Wilk Test.

Statistical analysis was conducted with the use of Statistica 13 (StatSoft).

\section{RESULTS}

In the years 2002-2014, 1148 patients underwent vaginal removals of non-prolapsed uteri with benign pathologies in the Clinic of Surgical, Endoscopic and Oncological 
Table 1. General characteristics of all patients who underwent vaginal hysterectomy of non-prolapsed uteri with benign pathologies in the years 2002-2014

\begin{tabular}{|c|c|c|c|c|}
\hline & Number & Percentage & Average \pm standard deviation & Range \\
\hline Average age, years, range & 1148 & & $49.65 \pm 6.92$ & $(19-80)$ \\
\hline Average BMI $\left(\mathrm{kg} / \mathrm{m}^{2}\right)$, range & & & $27.495 \pm 5.51$ & $(16.4-60.44)$ \\
\hline Underweight (BMI < 18.5) & 6 & $0.52 \%$ & & \\
\hline Normal (BMI 18.5-24.99) & 426 & $37.11 \%$ & & \\
\hline Overweight (BMI 25.0-29.99) & 407 & $35.45 \%$ & & \\
\hline Obese ( $\mathrm{BMI}>30$ ) & 309 & $26.92 \%$ & & \\
\hline \multicolumn{5}{|l|}{ Surgical history } \\
\hline Abdominal Surgeries & 284 & $24.74 \%$ & & \\
\hline Laparoscopic surgeries & 47 & $4.09 \%$ & & \\
\hline Vaginal surgeries & 25 & $2.18 \%$ & & \\
\hline No surgeries & 793 & $69.08 \%$ & & \\
\hline \multicolumn{5}{|l|}{ Obstetric history } \\
\hline Nullipara & 37 & $3.22 \%$ & & \\
\hline Previous Deliveries & 1111 & $96.78 \%$ & & \\
\hline Physiologic Delivery & 1059 & $92.25 \%$ & & \\
\hline Forceps Delivery & 11 & $0.96 \%$ & & \\
\hline Caesarean Section & 127 & $11.06 \%$ & & \\
\hline
\end{tabular}

$\mathrm{BMI}$ - body mass index

Gynecology of the Polish Mother's Memorial Hospital Research Institute (ICZMP) in Lodz (Tab. 1).

The average age of patients was 49 years and 7 months \pm 7 years. The most frequently operated patients were 50 years old while the median was 49 years.

A large group of patients were women with improper body weight. The average body mass index (BMI) of operated women was $27.50 \pm 5.51$. The number of patients with the normal weight (BMI 18.5-24.99) was 425, which constituted $37.11 \%$. Whereas the women who were overweight (BMI 25.0-29.99) and obese (BMI > 30) constituted 35.45\% and $26.92 \%$ of all operated patients. Only six women were underweight (0.52\%) with the body mass index below 18.4 .

Among all the patients who underwent vaginal hysterectomy close to $1 / 3$ of women had previous surgical history of surgeries in the abdomen and pelvis minor, out of which $24.74 \%$ were abdominal surgeries, $4.09 \%$ laparoscopic surgeries and $2.18 \%$ vaginal surgeries.

The number of patients with previous physiologic deliveries equaled 1059 , which constituted $92.25 \%$ of all operated patients (Tab. 1). Instrumental and surgical deliveries (forceps or Caesarean Sections) occurred much less frequently, $0.96 \%$ and $11 \%$ respectively. Eight women gave birth both physiologically and with the use of forceps, whereas there were 76 patients who had both natural childbirth and Caesarean Section. Two patients reported that in the past they had Caesarean Section and forceps delivery.
The largest group of patients were multiparas after two deliveries, who constituted $51.66 \%$ of all operated women. Only two patients qualified for vaginal hysterectomy had as many as seven deliveries.

In case of each surgery, the size and weight of the uterus played the key role when selecting the appropriate operating method. In most cases, the volume of the removed uterus was $182.67 \mathrm{~cm}^{3} \pm 159.91$, with the average of $141.88 \mathrm{~cm}^{3}$. The average weight of the removed organ was $179.69 \pm 113.54 \mathrm{~g}$. If we assume that the average weight of a normal uterus is usually between 50 and $100 \mathrm{~g}$, then the median weight of the removed uterus in this study was $150.74 \mathrm{~g}$. The largest uterus removed vaginally had the volume of $1483 \mathrm{~cm}^{3}$ and the weight of $1102.96 \mathrm{~g}$ and despite such considerable size the operation lasted only 75 minutes. In the analysed material, in as many as 150 patients the removed uteri weighed more than $280 \mathrm{~g}$, which is equal in size to the uterus at more than 12 weeks pregnant.

Additionally, when analyzing the size and weight of the operated uterus, the patients were divided into three groups (Tab. 2). The largest group (as many as 998 patients) consisted of women whose uteri weighed up to $280 \mathrm{~g}$, which was the size of uteri corresponding approximately to that at 12 weeks of pregnancy. Much larger uteri weighing more than $280 \mathrm{~g}$ (including 16 uteri of more than $580 \mathrm{~g}$ with the fundus reaching higher than the navel) were also removed using vaginal hysterectomy. 
Table 2. The analysis of particular parameters depending on the size and weight of the removed uterus

\begin{tabular}{|c|c|c|c|c|c|c|c|}
\hline & \multicolumn{2}{|c|}{ Uterus- below $280 \mathrm{~g}(\mathrm{n}=998)$} & \multicolumn{2}{|c|}{ Uterus- $280-579 \mathrm{~g}(\mathrm{n}=134)$} & \multicolumn{2}{|c|}{ Uterus- above $580 \mathrm{~g}(\mathrm{n}=16)$} & \multirow{2}{*}{$\begin{array}{l}\text { Significance } \\
\text { factor (p) }\end{array}$} \\
\hline & average & deviation & average & deviation & average & deviation & \\
\hline Average operating time [min] & 68.71 & 28.07 & 74.17 & 30.05 & 80.06 & 23.72 & 0.0170 \\
\hline $\begin{array}{l}\text { Average hemoglobin decrease } \\
\text { [g\%] }\end{array}$ & 1.17 & 0.95 & 1.15 & 1.02 & 1.90 & 2.01 & 0.3345 \\
\hline $\begin{array}{l}\text { Average hematocrit decrease } \\
{[\%]}\end{array}$ & 3.83 & 2.77 & 3.79 & 2.99 & 5.79 & 5.66 & 0.3969 \\
\hline $\begin{array}{l}\text { Average postoperative hospital } \\
\text { stay [days] }\end{array}$ & 2.90 & 1.39 & 3.16 & 2.88 & 3.06 & 1.61 & 0.2750 \\
\hline Cases with complications & \multicolumn{2}{|c|}{$16(1.60 \%)$} & \multicolumn{2}{|c|}{4 (2.98\%) } & \multicolumn{2}{|c|}{$2(12.50 \%)$} & 0.0044 \\
\hline
\end{tabular}

The performed analysis showed that the average operating time in case of uteri with a normal weight was $68.71 \pm 28.07$ minutes and was the shortest of all in comparison to the other two groups. The heavier the uterus, the longer the operating time. On average, the longest operation lasted $80.06 \pm 23.72$ minutes in the group of patients with the uteri heavier than $580 \mathrm{~g}$. This correlation was statistically significant, and the significance factor was $p=0.017$.

The postoperative changes in the levels of hemoglobin and hematocrit were also observed; however, these parameters were not statistically significant. The biggest drop of hemoglobin and hematocrit was registered when removing uteri heavier than $580 \mathrm{~g}$; it was $1.89 \pm 2.01 \mathrm{~g} \%$ for $\mathrm{Hb}$ and $5.79 \pm 5.66 \%$ for HCT respectively. Also, in this case, the lowest values of the evaluated parameters were observed in patients with the uteri weighing less than $280 \mathrm{~g}$; they were $1.17 \pm 0.95 \mathrm{~g} \%$ for hemoglobin and $3.83 \pm 2.77 \%$ for hematocrit.

The number of adverse events $(n=16)$ was higher in case of women with the uteri weighing less than $280 \mathrm{~g}$; however, due to the numerousness of this group, it constituted the lowest percentage of complications in comparison to the other groups. The majority of complications after vaginal removal of uteri weighing less than $280 \mathrm{~g}$ were the occurrence of a hematoma bigger than $5 \mathrm{~cm}$ in the abdominal cavity in 10 patients, most of whom received outpatient antibiotic treatment and were under observation. Another complication in this group of women was heavy vaginal bleeding observed in 8 patients, who required postoperative wound revision in the first 24 hours since the operation. Additionally, out of a whole group of women with the uteri lighter than $280 \mathrm{~g}$ only one woman suffered from damage to urinary bladder. It was noticed and treated during the operation of vaginal removal of the uterus. In women with the uteri weighing 280-579 g, four complications were recorded, which on a scale of this group gave $2.98 \%$ of adverse events. The complications mentioned included two cases of fever above 38 Celsius degrees, one case of intraoperative damage to the urinary bladder (noticed and treated during the operation) and one case where the patient required postoperative wound revision in the first 24-hours due to heavy vaginal bleeding.

In the group of women with the uteri heavier than $580 \mathrm{~g}$, there were two complications recorded, which in a group that small constituted as much as $12.5 \%$ of all events. This parameter was statistically significant $(p=0.0044)$. In this group of patients, one complication was a hematoma bigger than $5 \mathrm{~cm}$ in the abdominal cavity, and the other the occurrence of rectovaginal fistula.

\section{DISCUSSION}

Modern minimally invasive techniques such as a vaginal or laparoscopic method are gradually replacing classical methods in gynecology. Most world associations, including American Association ACOG, admit that the choice of operating techniques should depend not only on autonomous factors and patient's preferences but also on the experience, skills and constant training of the operating doctor [6]. The above-mentioned association ACOG, established that it is safe to perform vaginal removal of the uterus when it is smaller than the size at 12 weeks of pregnancy or weighs less than $280 \mathrm{~g}[7,8]$. Many experienced gynecologists, including the authors of studies such as Seth and Kovac, can safely remove a much bigger uterus using the method of vaginal morcellation.

According to the data coming from our clinic, in the years 2002-2014, 150 uteri with the size corresponding to that at 12 weeks pregnant were removed vaginally, which constituted $13 \%$ of all the performed vaginal hysterectomies. In this study, the largest removed uterus had the volume of $1123.71 \mathrm{~cm}^{3}$ and weighed $1102.96 \mathrm{~g}$.

Davies et al., as well as Mazdisnian et al., analysed vaginal removal of enlarged uteri. They successfully removed a uterus the size at 12 weeks of pregnancy without increasing perioperative complications, blood loss, the operating time and the length of postoperative hospital stay [9]. Unger et al. [10], who removed uteri weighing between 200 and 700 g, achieved 
similar results without increasing perioperative complications which occurred in case of abdominal hysterectomy.

In the material analysed in this study, the operating time and the percentage of adverse events were statistically significant only when removing very large uteri weighing more than $580 \mathrm{~g}$. However, neither an increased hemoglobin or hematocrit loss nor the lengthening of postoperative hospital stay were observed after these procedures regardless of the uterine size.

\section{CONCLUSIONS}

Vaginal hysterectomy is a relatively safe operating technique even for patients with uterine hypertrophy. Although the size and weight of the removed uterus had a significant influence on the operating time and the increased number of perioperative complications, vaginal removal is not a contraindication even in case of large uteri of more than $1000 \mathrm{~g}$. However, it should be kept in mind that a large uterus requires experience on the part of operating doctor.

\section{Conflict of interests}

The authors declare that they have no conflict of interests.

\section{REFERENCES}

1. Mohan Y, Chiu VY, Lonky NM. Size matters in planning hysterectomy approach. Womens Health (Lond). 2016; 12(4): 400-403, doi: 10.1177/1745505716653692, indexed in Pubmed: 27638893.

2. Hoyer-Sorensen $C$, Hortemo S, Lieng M. Changing the route of hysterectomy into a minimal invasive approach. ISRN Obstet Gynecol. 2013; 2013:249357, doi: 10.1155/2013/249357, indexed in Pubmed: 23762574.

3. Malinowski A, Maciołek-Blewniewska G. Dlaczego histerektomia pochwowa? Ginekol Pol. 2007; 78: 434-442.

4. Sheth SS. Vaginal or Abdominal Hysterectomy? In: Vaginal Hysterectomy. Vaginal Hysterectomy. 2nd Edition. Jaypee Brothers, New Delhi 2014: 273-293.

5. Malinowski A, Cieślak J. Anatomiczne aspekty pochwowej histerektomii. In: Cieślak J. ed. Zaawansowane techniki operacyjne w ginekologii- hysterektomia. LCL, Łódź 2007: 47-59.

6. Sirota I, Tomita SA, Dabney L, et al. Overcoming barriers to vaginal hysterectomy: An analysis of perioperative outcomes. J Turk Ger Gynecol Assoc. 2019; 20(1): 8-14, doi: 10.4274/jtgga.galenos.2018.2018.0021, indexed in Pubmed: 30209028.

7. Humes JC, Weir L, Keyser EA, et al. The Dying Art of Vaginal Hysterectomy: A Novel Simulation. Cureus. 2019; 11(12): e6362, doi: 10.7759/cureus.6362, indexed in Pubmed: 31938645.

8. Kovac SR. Clinical opinion: guidelines for hysterectomy. Am J Obstet Gynecol. 2004; 191(2):635-640, doi: 10.1016/j.ajog.2004.05.080, indexed in Pubmed: 15343253.

9. McCracken G, Lefebvre GG. Vaginal hysterectomy: dispelling the myths. J Obstet Gynaecol Can. 2007; 29(5):424-428, doi: 10.1016/S17012163(16)35494-9, indexed in Pubmed: 17493374.

10. Bhadra B, Choudhury AP, Tolasaria A, et al. Non Descent Vaginal Hysterectomy (NDVH): Personal Experience in 158 Cases. Al Ameen J Med. Sc. $2011 ; 4(1)$ 